\title{
Communication
}

\section{Though not Reservoirs, Dogs might Transmit Leptospira in New Caledonia}

\section{Noellie Gay, Marie-Estelle Soupé-Gilbert and Cyrille Goarant*}

Institut Pasteur in New Caledonia, 9-11 avenue Paul Doumer, BP 6198845 NOUMEA Cedex, New Caledonia; E-Mails: ngay@pasteur.nc (N.G.); msoupe@pasteur.nc (M.-E.S.-G.)

* Author to whom correspondence should be addressed; E-Mail: cgoarant@pasteur.nc; Tel.: +33-687-277-531; Fax: +33-687-273-390.

Received: 22 January 2014; in revised form: 26 March 2014 / Accepted: 28 March 2014 / Published: 17 April 2014

\begin{abstract}
Leptospira has been a major public health concern in New Caledonia for decades. However, few multidisciplinary studies addressing the zoonotic pattern of this disease were conducted so far. Here, pig, deer and dog samples were collected. Analyses were performed using molecular detection and genotyping. Serological analyses were also performed for dogs. Our results suggest that deer are a reservoir of L. borgpetersenii Hardjobovis and pigs a reservoir of L. interrogans Pomona. Interestingly, $4.4 \%$ of dogs were renal carriers of Leptospira. In dog populations, MAT results confirmed the circulation of the same Leptospira serogroups involved in human cases. Even if not reservoirs, dogs might be of significance in human contamination by making an epidemiological link between wild or feral reservoirs and humans. Dogs could bring pathogens back home, shedding Leptospira via their urine and in turn increasing the risk of human contamination. We propose to consider dog as a vector, particularly in rural areas where seroprevalence is significantly higher than urban areas. Our results highlight the importance of animal health in improving leptospirosis prevention in a One Health approach.
\end{abstract}

Keywords: Leptospira; epidemiology; mammal; dog; reservoir; vector 


\section{Introduction}

Leptospirosis is a widespread zoonosis in the tropics and notably the Pacific Islands [1,2]. It has been a major public health concern in New Caledonia (NC) for decades and was notably classified as a notifiable disease in 1991. Humans get infected when abraded skin or mucous membranes come into contact with contaminated kidneys, urine or urine-contaminated environments [3].

Leptospira strains are maintained in different animal species and excreted in the urine of asymptomatic chronically infected individuals [4,5]. Virtually any mammal species can act as a reservoir, characterized by a sustained non-symptomatic renal carriage [6] of a co-adapted Leptospira strain [4]. When not co-adapted, Leptospira do not chronically colonize kidneys of mammals, then considered as accidental hosts and frequently showing clinical signs when infected. At a population scale, a low prevalence of renal carriage (around or below 1\%) is expected in accidental hosts whereas it can reach more than $10 \%$ in reservoir populations [7]. Exposure to various mammals was found to be a risk for human leptospirosis in NC [8], namely rodents, horses, cattle and pigs and the role of indirect contamination via environmental exposure was highlighted [9].

Few mammals are present in NC: nine bat species, all indigenous, four introduced rodents (Rattus exulans, Rattus rattus, Rattus norvegicus and Mus musculus) and some introduced domestic mammals such as dog, cat, cattle, horse, goat and Rusa deer (Rusa timorensis) [10]. Two Leptospira species circulate in NC: L. interrogans and L. borgpetersenii [11] including five and two genotypes, respectively [12]. These are L. interrogans serogroups (sg) Icterohaemorrhagiae (accounting for $c a$. $50 \%-60 \%$ of human cases yearly), Pomona (ca. 5\%), Pyrogenes (15\%-25\%), Australis (5\%-10\%), Bataviae $(<5 \%)$ and L. borgpetersenii sg Ballum (ca. 10\%) and serovar Hardjobovis (never evidenced in human cases) [12]). Thus, paralleling its limited mammal diversity, NC also presents a low diversity of pathogenic Leptospira compared to inland countries or its neighbor Australia (http://www.health.gov.au/internet/main/publishing.nsf/Content/cda-phlncd-leptospirosis.htm). Despite extensive surveillance for more than two decades and serological surveys using the Microscopic Agglutination Test [9], some strains otherwise widely distributed were never evidenced in NC. Of note, serogroup Canicola, which reservoir is dog worldwide [13] was never evidenced in NC.

Rodents are recognized as the most significant reservoir of leptospires worldwide [3,5,14]. The overall prevalence of Leptospira spp. in rodents from NC was $26.7 \%$ [15]. Higher rodent abundance and Leptospira prevalence were evidenced during hot rainy periods. No difference between species was found, however, commensal species ( $R$. norvegicus and $M$. musculus) had a higher prevalence than sylvatic rodents [15]. Mice maintain L. borgpetersenii sg Ballum and Norway rats are the reservoir of $L$. interrogans sg Icterohaemorrhagiae. Laboratory diagnoses of human cases are performed at the reference laboratory, Institut Pasteur de Nouvelle-Calédonie, which provides biological data to the Health authority for epidemiological surveillance purpose. Surveillance data show that leptospires involved in the majority of human cases in NC are maintained by rodents (Icterohaemorrhagiae in the three rat species and Ballum in the mice and some black rats [15]), but that three other genotypes, corresponding to serogroups Pomona, Pyrogenes and Australis, were also involved in a significant number of human cases [12].

The mammal reservoirs of these latter Leptospira are currently investigated using molecular approaches similar to the ones used for characterizing human cases [12,16] and the rodent 
reservoir [15]. Thus, a field-to-laboratory survey was set up to update data on pathogenic Leptospira carriage by animals in NC. To achieve this goal, we estimated the prevalence of renal infection by Leptospira in deer, pigs and dogs and genotyped the strains evidenced in these animals.

\section{Experimental Section}

From March to October 2013, a total of 519 samples were collected for molecular analysis. Pig and deer kidneys were sampled at slaughterhouses in Paita and Bourail, respectively. Samples from feral pigs and deer were collected by the Conservatoire des Espaces Naturels responsible for the environmental management of invasive species in NC. Eighty two dog kidney samples were obtained from the pound of Nouméa (urban dogs), 13 dog urine specimens were from apparently healthy dogs sampled in various tribes (one from Poindimié and 12 from Houailou).

Animals from slaughterhouses were considered as clinically healthy when sampled because preslaughter veterinary controls systematically apply in slaughterhouses. Pound-euthanized dogs were all stray dogs, but also apparently healthy. They had been kept captive for at least eight days in the pound, where rodent control is regularly implemented. Therefore, if dogs in the pound were infected by Leptospira, the contamination was considered to be acquired before capture. Urine samples were collected from live apparently healthy animals, buffered with 10\% 10X phosphate buffer saline and stored in a cool box until transfer to the laboratory for direct DNA extraction. Kidney samples were immediately placed and stored in 95\% alcohol for postponed DNA extraction as described before [15]. A single sample from one kidney was taken from each individual animal and was considered as representative of the animal kidneys.

Dog venous blood was collected immediately after death for serology from 31 urban dogs at the pound of Nouméa in 2010-2011 and from 47 live rural dogs in 2013 (mostly from tribes in the Northern Province in Hienghène, Houailou and Ouégoa).

\subsection{DNA Extraction}

A small piece of kidney tissue (ca. $25 \mathrm{mg}$ ) was dissected and rehydrated overnight in 1,000 $\mu \mathrm{L}$ sterile water at $4{ }^{\circ} \mathrm{C}$. Water was then removed; $50 \mu \mathrm{L}$ of $1 \mathrm{X}$ sterile phosphate buffer saline was added to the kidney sample before DNA extraction using the QIAamp DNA mini kit (QIAGEN, Auckland, New Zealand) following manufacturer's instructions for tissue. Urine samples were extracted following manufacturer's instructions. All DNA concentrations were standardized to $50 \mathrm{ng} / \mu \mathrm{L}$ after measurement of the concentration with a NanoDrop 2000 (Thermo Scientific, Scoresby, Victoria, Australia).

\subsection{Molecular Tools}

Leptospira was detected using two different real time PCRs, both targeting lipL32 [17,18]. If the sample tested positive, the lfb1 gene was amplified using SYBR Green technology [19]. To check for the absence of inhibitors that could lead to false negative results, every negative DNA sample was amplified with a universal $16 \mathrm{~S}$ rDNA PCR. The ones containing inhibitors were repeatedly extracted and submitted to amplification. If the second DNA extract also contained inhibitors, the sample was not considered in the analysis. 


\subsection{Leptospira Genotyping by Sequencing}

The Ifb1 amplification products from positive samples were purified using the MinElute PCR purification kit (QIAGEN) and directly sequenced for genotyping as described by Perez et al. [12].

\subsection{Serology}

Microscopic Agglutination Tests (MAT) were used to check 78 dog sera for Leptospira-specific antibodies with the local panel used for human diagnosis [8] using a 1:100 positivity threshold. This MAT panel was developed and optimized for leptospirosis diagnosis in New Caledonia and is described in Table 1.

Table 1. New Caledonian panel of Leptospira strains used for the MAT.

\begin{tabular}{cccc}
\hline Species & Serogroup & serovar & Strain \\
\hline L. interrogans & Australis & Australis & Ballico \\
L. interrogans & Autumnalis & Autumnalis & Akiyami A \\
L. borgpetersenii & Ballum & castellonis & Castellon 3 \\
L. interrogans & Bataviae & Bataviae & Van Tienen \\
L. interrogans & Canicola & Canicola & Hond Utrecht \\
L. interrogans & Icterohaemorrhagiae & Icterohaemorrhagiae & Verdun \\
L. interrogans & Icterohaemorrhagiae & Copenhagenii & Winjberg \\
L. noguchi & Panama & Panama & CZ 214 K \\
L. interrogans & Pomona & Pomona & Pomona \\
L. interrogans & Pyrogenes & Pyrogenes & Salinem \\
L. borgpetersenii & Tarassovi & Tarassovi & Mitis Johnson \\
L. biflexa & Semarranga & Patoc & Patoc I \\
\hline
\end{tabular}

Following standard recommendations, the infecting serogroup was designated as the serogroup of the strain with a titer at least 4-fold the titer of the other strains. When this was not possible (co-agglutinations or highest titers with the non-pathogenic L. biflexa Patoc I), the MAT was considered as positive for an unidentified serogroup. Statistical analyses were computed with $\mathrm{R}$ software and Fisher's exact tests were used.

\section{Results}

\subsection{Leptospira Carriage}

From qPCR amplification, 14 kidney DNA extracts demonstrated PCR inhibitors and were not integrated in statistical analysis (nine deer, four dogs, one pig).

Pathogenic Leptospira renal carriage was detected in all three species investigated. The detailed results are shown in Table 2 . The prevalence was highly variable depending on the species, being as high as $13 \%$ in deer, reaching $8.7 \%$ in pigs and $4.4 \%$ in dogs. 
Table 2. Distribution of Leptospira among mammals sampled

\begin{tabular}{|c|c|c|c|c|c|c|c|}
\hline Mammal & Source & Sample size & PCR inhibition & Positive & Negative & Prevalence & 95\% CI \\
\hline \multirow{2}{*}{ Deer * } & Hunting & 85 & \multirow{2}{*}{9} & \multirow{2}{*}{25} & \multirow{2}{*}{167} & \multirow{2}{*}{13.02} & \multirow{2}{*}{ [8.26-17.78] } \\
\hline & Slaughtered & 107 & & & & & \\
\hline \multirow{2}{*}{ Pig * } & Feral & 94 & 0 & 6 & 88 & 6.38 & [1.44-11.32] \\
\hline & Farmed & 138 & 1 & 14 & 123 & 10.22 & [5.15-15.29] \\
\hline \multirow{2}{*}{ Dog } & Urban pound (kidney) & 82 & 4 & 3 & 75 & & \multirow{2}{*}[0.19-8.61]{} \\
\hline & Tribes (urine) & 13 & 0 & 1 & 12 & & \\
\hline
\end{tabular}

* Because deer are captured from feral populations and only ranched for a few days or weeks before slaughter, hunted or slaughtered deer should not be considered as distinct populations. Oppositely, feral and farmed pigs are distinct populations, providing the opportunity to evaluate the prevalence in both populations.

\subsection{Strain Identification by Genotyping}

The molecular identification of strains provided information about the infecting Leptospira at the species and serogroup level (Figure 1). The majority of Leptospira evidenced in deer were L. borgpetersenii, the DNA sequence pointing to Hardjobovis and positive pigs were mostly carriers of L. interrogans, the sequence pointing to sg Pomona. In dogs, both L. interrogans sg Pomona (one rural dog and one urban dog) and L. interrogans sg Icterohaemorrhagiae (two urban dogs) were evidenced.

Figure 1. Leptospira identification among positive Mammals.

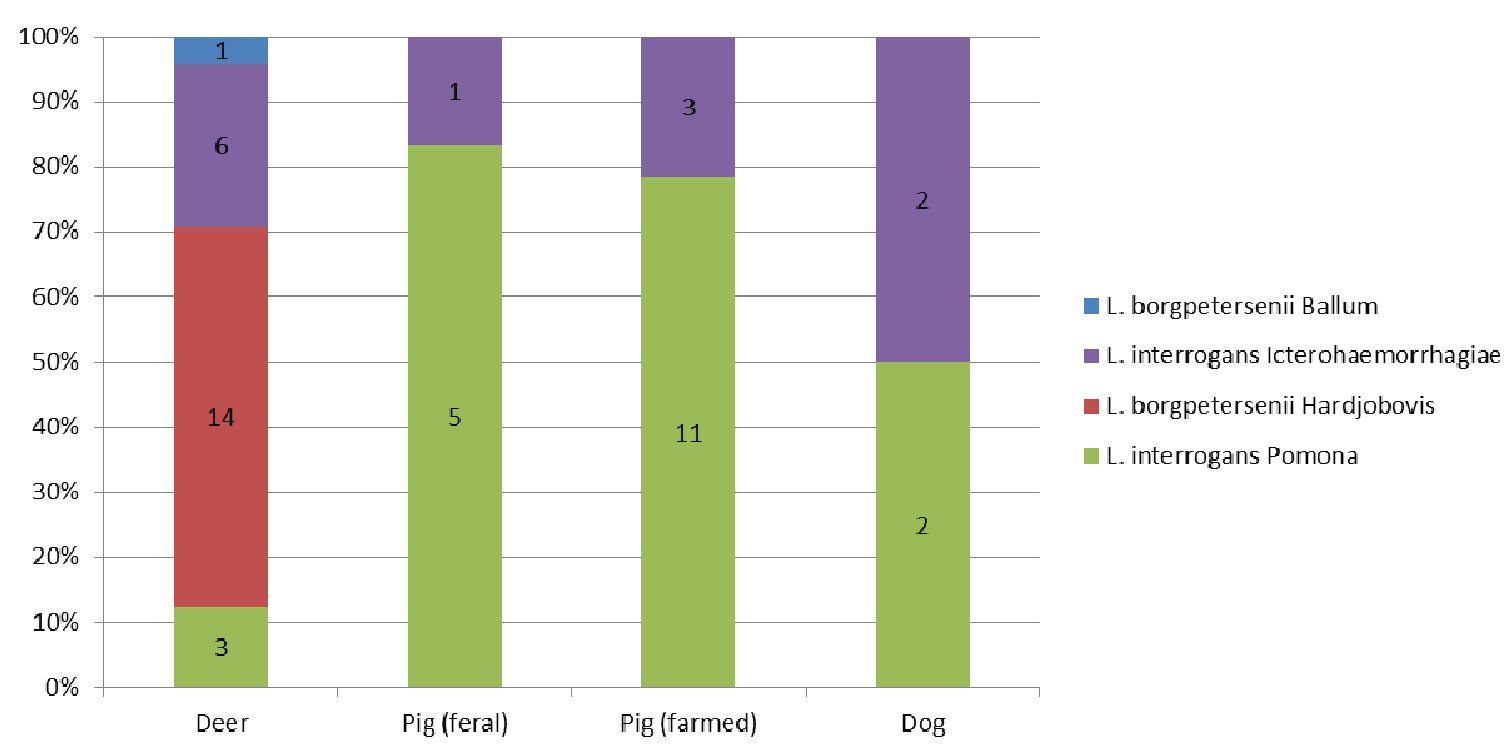

\subsection{MAT on Dog Sera}

Overall $24(30.8 \%)$ of the 78 dog sera tested were found seropositive with MAT. From 31 urban dogs from the pound, four were reactive with sg Icterohaemorrhagiae (Table 3). The majority of sera from rural dogs were seropositive for sg Australis and Icterohaemorragiae (Table 3). Seroprevalence was significantly higher for rural dogs $(p<0.005)$. 
Table 3. Putative serogroup in MAT-positive dogs according to their origin.

\begin{tabular}{cccccc}
\hline Putative Serogroup & Australis & Icterohaemorrhagiae & Canicola & Pyrogenes & Unknown * \\
\hline Urban dogs $(n=31)$ & 0 & 4 & 0 & 0 & 1 \\
Rural dogs $(n=47)$ & 3 & 11 & 0 & 1 & 4 \\
\hline \multicolumn{5}{c}{ co-agglutinations or highest titre for non-pathogenic L. biflexa Patoc. }
\end{tabular}

\section{Discussion}

In our study, deer were identified as a reservoir of $L$. borgpetersenii Hardjobovis as suggested by Perez et al. [12] in a former study. Interestingly, despite frequent interactions between deer and hunters, L. borgpetersenii Hardjobovis has never been identified in human cases in New Caledonia [12]. Whether it is exclusively transmitted between animals or if it induces only few symptoms in humans, resulting in an underreporting, remains to be determined. Additionally, deer were probably involved in the circulation of Pomona in NC, though more investigations are needed to better understand the role of deer in Pomona maintenance and circulation.

Among Leptospira positive pigs, most carried L. interrogans sg Pomona, whether farmed or feral. Thus, pigs might be a reservoir of this serogroup in NC as reported in New Zealand [20]. Interestingly, in 2013,8\% of human leptospirosis cases in NC involved L. interrogans sg Pomona (our unpublished data). Consequently, prevention measures should be encouraged to limit contacts of humans with pig manure or with kidneys and urine at slaughter. Our results also suggest that both deer and pigs (feral or farmed) are exposed to rodent-borne leptospirosis, as evidenced by some carriage of Icterohaemorrhagiae or Ballum, maintained by rats and mice [15].

In our study, Leptospira renal carriage prevalence in dogs was 4.4\%, molecular identification of the infecting strains pointing to L. interrogans sg Pomona and Icterohaemorrhagiae. This survey again failed to evidence any Canicola, further suggesting its absence in New Caledonia. And yet, it is usually considered that dogs are susceptible to Pomona and Icterohaemorrhagiae rather than possible reservoirs $[13,21]$, though possible chronic carriage of Pomona in some dogs is still a matter of debate. However, in our study, the animals surveyed displayed no clinical symptoms when sampled. The three dogs from the pound were active and apparently healthy for at least 8 days as they were caught wandering at least one week before euthanasia. These dogs were most probably at a late stage of a non-lethal leptospirosis, currently recovering but still carrying leptospires in their kidneys and shedding it in their urine. It is recognized that Leptospira excretion in urine might be intermittent. As a result, the detection of carrier animals using urine specimens might be less a sensitive technique when compared with detection from kidney tissue. Because rural dogs had to be sampled live, we could only obtain urine specimens, possibly under-regarding the prevalence in this particular canine population.

This survey confirms that dogs are most probably not a reservoir host for Leptospira in NC as the prevalence was low and serogroup Canicola was not identified in any specimen. However, a significant proportion of dogs were carrying pathogenic leptospires in their kidneys. We hypothesise that at a population scale, though not maintenance hosts, dogs are probably involved in the circulation of pathogenic Leptospira. Our results suggest that these dogs were infected after direct or indirect contact with pig, deer or rats, or with another infected dog. Such dogs might be regarded as "vectors": 
this mammal, living in close contact with humans, is exposed to various sources of direct or environmental contamination and is more likely to interact with both other mammal reservoirs (hunting, wandering) and humans. Dogs are highly exposed to zoonotic and environmental contamination and could bring pathogens back home, shedding Leptospira via their urine in the household environment and in turn increasing the risk of human contamination. Further supporting our hypothesis, MAT results confirmed the circulation in dog populations of the same Leptospira strains involved in human cases (sg Icterohaemorrhagiae, Australis and Pyrogenes being the most prevalent) [12]. This particular role for dogs was already suggested in other places. In the island of Barbados, where Canicola is also absent, epidemiological data using serology suggests a similar role for dogs in transmitting leptospirosis from a wild and environmental reservoir to humans [22]. An increase in human leptospirosis in Germany was linked to a resurgence of canine leptospirosis [23]. In Nicaragua, patients were significantly more likely than controls to own seropositive dogs [24,25], again suggesting transmission between dogs and their owners or contamination from a common source. Our study, by evidencing renal carriage of pathogenic Leptospira using molecular detection and typing, strongly supports this role of dogs as an epidemiological link between the environment, wild fauna and humans.

Rural environments are thought to pose a higher risk of infection for dogs because of more frequent interactions with wildlife and watered environments [26]. Our molecular survey mostly included urban dogs $(86 \%)$ and cannot statistically address this specific issue. However, our serological results confirm a significantly higher seroprevalence in rural $(40.4 \%)$ than in urban $(16.1 \%)$ dogs $(p<0.005)$, reinforcing the hypothesis that rural dogs could be a risk for human leptospirosis in NC. Improving the awareness of dog owners and the prevention of canine leptospirosis, particularly in rural places, could be a valuable asset for human leptospirosis prevention.

Leptospirosis infection in dogs can be treated with appropriate antibiotics, which are effective in preventing urinary shedding [27]. The control of dog populations using castration might also prove useful in reducing Leptospira circulation, as suggested by Yoak and collaborators [28]. Lastly, it has been shown that vaccination could induce a protection against both clinical leptospirosis and renal carriage and shedding [29]. As observed in our survey in NC, the serovar Pomona was increasingly identified in dogs in North America [26,30] and Europe [31] leading to the inclusion of the Pomona valence in a new dog vaccine in North America [32]. If effective in preventing renal carriage and urinary shedding, this new vaccine could be used in New Caledonian dogs and could improve prevention for both dogs and owners. Consequently, the role of animal health in public health needs to be considered in a One Health approach. As suggested before [33], the implementation of a surveillance system for canine leptospirosis, using dogs as sentinels for human risk assessment, could also provide a valuable tool for estimating and in turn minimizing the risk for humans.

\section{Conclusions}

Our results suggest that dogs are not a Leptospira reservoir host and further failed to identify Canicola (using both serological and molecular tools), a serogroup most probably absent in NC. However, dogs may, during recovery from mild Leptospira infections, contribute to human leptospirosis by bringing pathogenic strains closer to humans and their households. We propose to 
consider dogs as vectors, ensuring the link from primary animal reservoirs to humans through their role as companion animals. The contribution of dogs, particularly in rural settings, as a vector between wild or feral reservoirs and human should be further investigated.

\section{Acknowledgments}

Most specimens from feral deer and pig were obtained through an agreement between Institut Pasteur, Conservatoire des Espaces Naturels de Nouvelle-Calédonie, Institut Agronomique néo-Calédonien and Direction des Affaires Vétérinaires, Agro-alimentaires et Rurales. We thank our collaborators Patrick Barriere, Thomas Hue and Céline Marchal. We are also grateful to the NGO Dayu Biik for providing other samples of feral pigs and deer. The pound of Nouméa and the Office de Commercialisation et d'Entreposage Frigorifique are acknowledged for allowing us to collect dog, deer and pig samples. Drs Olivier Vilain and Yann Charpentier helped with sample collection on the field. Ilaïsa Keletaona, Stéphanie Laffont and Sophie Andruet perfomed the MAT on dog sera. Sequence reads were made at the "Plateforme du Vivant" under the supervision of Laurent Millet.

\section{Author Contributions}

Cyrille Goarant had the original idea for the study and, with all co-authors carried out the design. Noellie Gay and Marie-Estelle Soupé-Gilbert were responsible for collection and analysis of biological specimens. Noellie Gay and Marie-Estelle Soupé-Gilbert were responsible for data cleaning and carried out the analyses. Noellie Gay and Cyrille Goarant drafted the manuscript, which was revised by all authors. All authors read and approved the final manuscript.

\section{Conflicts of Interest}

The authors declare no conflict of interest.

\section{References}

1. Berlioz-Arthaud, A.; Kiedrzynski, T.; Singh, N.; Yvon, J.F.; Roualen, G.; Coudert, C.; Uluiviti, V. Multicentre survey of incidence and public health impact of leptospirosis in the Western Pacific. Trans. R. Soc. Trop. Med. Hyg. 2007, 101, 714-721.

2. Victoriano, A.F.; Smythe, L.D.; Gloriani-Barzaga, N.; Cavinta, L.L.; Kasai, T.; Limpakarnjanarat, K.; Ong, B.L.; Gongal, G.; Hall, J.; Coulombe, C.A.; Yanagihara, Y.; Yoshida, S.I.; Adler, B. Leptospirosis in the Asia Pacific region. BMC Infect. Dis. 2009, 9, doi:10.1186/1471-2334-9-147.

3. Adler, B.; de la Pena Moctezuma, A. Leptospira and leptospirosis. Vet. Microbiol. 2009, 140, 287-296.

4. Baranton, G.; Old, I.G. The spirochaetes: A different way of life. Bull. Inst. Pasteur. 1995, 93, 63-95.

5. Levett, P.N. Leptospirosis. Clin. Microbiol. Rev. 2001, 14, 296-326.

6. Babudieri, B. Animal reservoirs of leptospires. Ann. N.Y. Acad. Sci. 1958, 70, 393-413. 
7. Desvars, A. Epidémiologie d'une zoonose, la leptospirose, dans deux îles de l'Océan indien, la Réunion et Mayotte-Etude comparée du rôle de différentes espèces sauvages et domestiques. Ph.D. Thesis, Université de la Rénuion, Saint Denis, La Réunion, 26 April 2012.

8. Berlioz-Arthaud, A.; Merien, F.; Baranton, G. Laboratory based human leptospirosis surveillance in New Caledonia (2001-2005). Bull. Soc. Pathol. Exot. 2007, 100, 133-138. (In French)

9. Goarant, C.; Marchal, C.; Gourinat, A.-C. La surveillance de la leptospirose en Nouvelle-Calédonie: approche pluridisciplinaire d'une zoonose endémique. Bulletin épidémiologique, santé animale et alimentation 2011, 43, 22-25.

10. Gargominy, O.; Bouchet, P.; Pascal, M.; Jaffré, T.; Tourneur, J.-C. Conséquences des introductions d'espèces animales et végétales sur la biodiversité en Nouvelle-Calédonie. Rev. Ecol. (Terre Vie) 1996, 51, 375-402.

11. Salaün, L.; Merien, F.; Gurianova, S.; Baranton, G.; Picardeau, M. Application of multilocus variable-number tandem-repeat analysis for molecular typing of the agent of leptospirosis. J. Clin. Microbiol. 2006, 44, 3954-3962.

12. Perez, J.; Goarant, C. Rapid Leptospira identification by direct sequencing of the diagnostic PCR products in New Caledonia. BMC Microbiol. 2010, 10, doi:10.1186/1471-2180-10-325.

13. Andre-Fontaine, G. Canine leptospirosis-Do we have a problem? Vet. Microbiol. 2006, 117, $19-24$.

14. Vinetz, J.M. Leptospirosis. Curr. Opin. Infect. Dis. 2001, 14, 527-538.

15. Perez, J.; Brescia, F.; Becam, J.; Mauron, C.; Goarant, C. Rodent abundance dynamics and leptospirosis carriage in an area of hyper-endemicity in New Caledonia. PLoS Negl. Trop. Dis. 2011, 5, doi:10.1371/journal.pntd.0001361.

16. Goarant, C. Leptospirosis: Time to move to molecular epidemiology: Comments on "Reassessment of MLST schemes for Leptospira spp. typing worldwide" by Varni and colleagues. Infect. Genet. Evol. 2014, 21, 484-485.

17. Levett, P.N.; Morey, R.E.; Galloway, R.L.; Turner, D.E.; Steigerwalt, A.G.; Mayer, L.W. Detection of pathogenic leptospires by real-time quantitative PCR. J. Med. Microbiol. 2005, 54, $45-49$.

18. Stoddard, R.A.; Gee, J.E.; Wilkins, P.P.; McCaustland, K.; Hoffmaster, A.R. Detection of pathogenic leptospira spp. through TaqMan polymerase chain reaction targeting the LipL32 gene. Diagn. Microbiol. Infect. Dis. 2009, 64, 247-255.

19. Merien, F.; Portnoi, D.; Bourhy, P.; Charavay, F.; Berlioz-Arthaud, A.; Baranton, G. A rapid and quantitative method for the detection of Leptospira species in human leptospirosis. FEMS Microbiol. Lett. 2005, 249, 139-147.

20. Thornley, C.N.; Baker, M.G.; Weinstein, P.; Maas, E.W. Changing epidemiology of human leptospirosis in New Zealand. Epidemiol. Infect. 2002, 128, 29-36.

21. Goldstein, R.E. Canine leptospirosis. Vet. Clin. North Am. 2010, 40, 1091-1101.

22. Weekes, C.C.; Everard, C.O.; Levett, P.N. Seroepidemiology of canine leptospirosis on the island of Barbados. Vet. Microbiol. 1997, 57, 215-222.

23. Jansen, A.; Schoneberg, I.; Frank, C.; Alpers, K.; Schneider, T.; Stark, K. Leptospirosis in Germany, 1962-2003. Emerg. Infect. Dis. 2005, 11, 1048-1054. 
24. Trevejo, R.T.; Rigau-Perez, J.G.; Ashford, D.A.; McClure, E.M.; Jarquin-Gonzalez, C.; Amador, J.J.; de los Reyes, J.O.; Gonzalez, A.; Zaki, S.R.; Shieh, W.J.; et al. Epidemic leptospirosis associated with pulmonary hemorrhage-Nicaragua, 1995. J. Infect. Dis. 1998, 178, 1457-1463.

25. Douglin, C.P.; Jordan, C.; Rock, R.; Hurley, A.; Levett, P.N. Risk factors for severe leptospirosis in the parish of St. Andrew, Barbados. Emerg. Infect. Dis. 1997, 3, 78-80.

26. Ghneim, G.S.; Viers, J.H.; Chomel, B.B.; Kass, P.H.; Descollonges, D.A.; Johnson, M.L. Use of a case-control study and geographic information systems to determine environmental and demographic risk factors for canine leptospirosis. Vet. Res. 2007, 38, 37-50.

27. Langston, C.E.; Heuter, K.J. Leptospirosis: A re-emerging zoonotic disease. Vet. Clin. North Am. 2003, 33, 791-807.

28. Yoak, A.J.; Reece, J.F.; Gehrt, S.D.; Hamilton, I.M. Disease control through fertility control: Secondary benefits of animal birth control in Indian street dogs. Prev. Vet. Med. 2014, 113, 152-156.

29. Minke, J.M.; Bey, R.; Tronel, J.P.; Latour, S.; Colombet, G.; Yvorel, J.; Cariou, C.; Guiot, A.L.; Cozette, V.; Guigal, P.M. Onset and duration of protective immunity against clinical disease and renal carriage in dogs provided by a bi-valent inactivated leptospirosis vaccine. Vet. Microbiol. 2009, 137, 137-145.

30. Prescott, J.F.; McEwen, B.; Taylor, J.; Woods, J.P.; Abrams-Ogg, A.; Wilcock, B. Resurgence of leptospirosis in dogs in Ontario: Recent findings. Can. Vet. J. 2002, 43, 955-961.

31. Mayer-Scholl, A.; Luge, E.; Draeger, A.; Nockler, K.; Kohn, B. Distribution of Leptospira Serogroups in dogs from Berlin, Germany. Vector Borne Zoonotic Dis. 2013, 13, 200-202.

32. Ellis, W.A. Control of canine leptospirosis in Europe: Time for a change? Vet. Rec. 2010, 167, 602-605.

33. Davis, M.A.; Evermann, J.F.; Petersen, C.R.; Vanderschalie, J.; Besser, T.E.; Huckabee, J.; Daniels, J.B.; Hancock, D.D.; Leslie, M.; Baer, R. Serological survey for antibodies to Leptospira in dogs and raccoons in Washington State. Zoonoses Public Health 2008, 55, 436-442.

(C) 2014 by the authors; licensee MDPI, Basel, Switzerland. This article is an open access article distributed under the terms and conditions of the Creative Commons Attribution license (http://creativecommons.org/licenses/by/3.0/). 